\title{
Knowledge Ascription by Grammatical Construction
}

Laura A. Michaelis

University of Colorado at Boulder

\section{Introduction ${ }^{1}$}

While little consensus has emerged from the debate about the nature of know how, the parties do appear to agree about two things: first, folk conceptions of knowledge matter and second, linguistic analysis is a good way to get at those conceptions. Particular attention has been paid to the syntactic behavior of verbs of knowledge ascription. The rationale is presumably that a verb's grammatical frame (i.e., it complement structure) reveals its conceptual structure - in particular, the repertoire of semantic roles that it evokes - and therefore a theory that captures the syntactic behavior of knowledgeascription verbs will also explain what kind of relationship verbs of knowledge ascription express. Thus, for example, Stanley (2011) rejects the Rylean view of know-how in part because it must treat as accidental the fact that both procedural knowledge and propositional knowledge are expressed by clausal complements consisting of a question word followed by an infinitive, as in (1) versus (2), respectively:

1. She knows how to go.

2. She knows where to go.

The evidence suggests, however, that grammatical constructions do not provide a transparent window onto the meanings of verbs like know, because constructions can, and frequently do, alter the combinatoric potential of verbs with which they combine. As a straightforward illustration of this point, consider the activity verb sweep. It denotes a relation between a person and a surface in (3), but in (4) it denotes a relation between a person and a substance:

3. She swept the floor.

4. She swept the dirt into a dustpan.

The semantic difference between (3) and (4) is attributable to syntactic context: in (3) sweep occurs in a simple transitive construction while in (4) it occurs in a construction the expresses causation of motion. How do these observations apply to verbs of knowledge ascription? Taking the verb learn as illustrative of the class, I submit that one cannot reasonably infer from the usage in (5), in which learn clearly denotes a relation between a person and a proposition, that it denotes this same relation in either (6) or (7):

5. I learned that wider tires have better traction.

6. I learned to change a tire.

7. I learned how to change a tire.

Instead, as I will argue, (6) expresses a relation between a person and a procedure and (7) a relation between a person and a method of performing a procedure. In short, the

${ }^{1}$ The author gratefully acknowledges help and advice received from Marc Moffett, Knud Lambrecht, Josef Ruppenhofer and Adele Goldberg. 
argument roles that a verb assigns differ according to its syntactic context. Does this then mean that the syntactic behaviors of verbs cannot or should not inform our models of knowing how? To the contrary, I will argue, the observed syntactic variability suggests a compromise between the Rylean and Intellectualist views: knowledge-ascription verbs assign complements denoting propositions, as per the Intellectualist view, while infinitival constructions assign complements denoting actions, as per the Rylean view. The analysis that I will offer is based on Construction Grammar. According to Construction Grammar, rules of syntactic combination (like that which describes the noun phrase) are directly associated with interpretive and use conditions, in the form of semantic and pragmatic features that attach to the mother or daughter nodes in these descriptions (Goldberg 1995, Fillmore and Kay 1999, Kay 2002, Michaelis 2004, Sag 2010). This amounts to the claim that syntactic rules mean things. Meaning is generally viewed as the exclusive purview of words, and in the prevailing view of meaning composition, syntactic rules do no more than determine what symbol sequences function as units for syntactic purposes. So while syntactic rules assemble words and their dependent elements into phrases, and the phrases denote complex concepts like predicates and propositions, the rules cannot add conceptual content to that contributed by the words; nor can they alter the combinatoric properties of the words. On this view, which Jackendoff (1997: 48) describes as the "doctrine of syntactically transparent composition", "[a]ll elements of content in the meaning of a sentence are found in the lexical conceptual structures [...] of the lexical items composing the sentence". A major problem with this view is that, as first observed by Goldberg (1995), syntactic context can in fact alter the combinatoric potential of words, as shown by the following attested examples:

8. Down at the harbor there is a teal-green clubhouse for socializing and parties. Beside it sparkles the community pool. (Vanity Fair 8/01)

9. When a visitor passes through the village, young lamas stop picking up trash to mug for the camera. A gruff 'police monk' barks them back to work. (Newsweek $10 / 13 / 97)$

The verbs shown in boldface in (8-9), sparkle and bark, do not usually appear in these particular sentence patterns. By the same token, the sentence patterns exemplified in (8-9) usually contain verbs other than these. The pattern exemplified in (8), in which an intransitive verb precedes its subject and follows a location expression, favors verbs of location like sit and lie. The pattern exemplified in (9), in which a transitive verb is followed by both a direct object and a location expression, favors causative verbs that denote a change of location, e.g., move or push. The verb sparkle is not a verb of location; nor does bark express causation of motion. Counter to the predictions of the syntactically transparent composition, however, such verb-construction conflicts yield not gibberish but new verb meanings: the reader of (8) is inclined to interpret sparkling as the manner of location while the reader of (9) is likely to interpret barking as the (metaphorical) means by which motion is effected.

How are the verb-meaning shifts illustrated in (8-9) effected? Using basic tools of construction-based syntactic analysis, Goldberg (1995) provided a simple and conceptually satisfying answer: verb-construction conflict resolution. Her explanation starts with the foundational premise of Construction Grammar-that grammatical 
patterns like the ones exemplified in (8-9) have meanings, as indicated by the following analyses:

\section{Locative inversion construction}

Form: a locative expression (A) preceding a verb whose subject (B) follows the verb. Meaning: the location denoted by $\mathrm{A}$ has (or comes to have) entity $\mathrm{B}$, in it.

11. Caused motion construction

Form: a verb with a subject (A), object (B) and directional expression (C). Meaning: the entity denoted by A causes the entity denoted by $\mathrm{B}$ to go to $\mathrm{C}$.

Given these construction meanings, we can view the novel verb meanings in (8-9) as predictable by-products of verb-construction combination, or more specifically of verbconstruction conflict resolution - an inferential process in which a verb comes to denote the kind of event or state that the construction denotes (Michaelis 2004). In this process, the set of semantic roles associated with the verb is augmented up to that licensed by the construction, as when the verb sparkle acquires a location role. Since we need the locative-inversion and caused-motion constructions anyway, we do not need additional constructions to describe the special meanings in (8-9); nor do we need to create new verb definitions to describe those meanings. In order to reconcile the semantic contribution of verb and construction in such instances, the interpreter must relate the verb meaning to the construction meaning via what Goldberg (1995) calls an integration relation. Integration relations include manner, means and precondition. The manner and means relations are illustrated by (8-9), respectively, and the precondition relation will be illustrated below.

The construction-based model of argument structure resolves certain otherwise paradoxical properties of verbs. For example, while it seems a priori impossible for the verb bark to be transitive and intransitive at the same time, this apparent paradox disappears when we acknowledge the caused-motion construction as the source of the direct object in (9). Crucially for our purposes, the construction-based model of argument structure also suggests an intuitive way to resolve the conflict between the Rylean and Intellectualist positions: verbs of knowledge ascription do indeed, as claimed by the Intellectualists, take propositions as their second arguments, but whether or not that proposition actually surfaces as a complement will depend on the construction with which the verb combines. When, for example, verbs of knowledge-ascription verbs take bare infinitival complements, as in English I learned to drive or French Je sais conduire, they express a relation between a person and a procedure, as per the Rylean view, rather than a relation between a person and a proposition, as per the Intellectualist view. More generally, the appropriate semantic analysis of a verb of knowledge ascription will vary according to the complementation pattern in which the verb is encountered. As shown in (5-7), there are three major complementation patterns for verbs of knowledge ascription; those examples are repeated here as (12-14):

12. Clausal complement: I learned that wider tires have better traction.

13. Infinitival complement: I learned to change a tire.

14. WH-complement: I learned how to change a tire.

In all but (12), we will assume that the verb's proposition argument has been suppressed, and that the construction has supplied a distinct second argument. In the case of the 
infinitival-complement construction exemplified in (13), this second argument is a procedure. In the case of the WH-complement construction exemplified in (14), this second argument is a 'means' variable in an open proposition (i.e., 'One changes a tire in $\mathrm{x}$ manner'). The remainder of this paper will be devoted to these two English constructions and the manner in which they interact with verbs of knowledge ascription. Section 2 will provide an analysis of two major infinitival-complement constructions, Object Control and Subject Control. Section 3 will provide an analysis of the WH Complement construction. Section 4 will contain concluding remarks and a brief consideration of the functional contrast between the two apparently synonymous infinitive constructions exemplified in (13-14).

\section{Infinitival complements}

In arguing against the Rylean view of knowing how, Stanley (2011) points out that it entails a counterintuitive ambiguity for verbs of knowledge ascription. He states (p. 232):

The Rylean must argue that the English verb "know", and the French word "savoir", as well as their cognates in many other languages, are ambiguous between the propositional knowledge verb, and a verb attributing a distinct cognitive state, which is an attitude towards an action-type.

But in fact on a constructionist approach, savoir means the same thing in (15) and (16):

\section{Je sais qu'il a raison.}

'I know that he is right.'

16. Je sais nager.

'I know how to swim.'

Only the construction-integration relations are different in the two cases. Let us concur with Stanley that knowing is a relationship between a person and a proposition. This does not mean, however, that the construction in which a verb of knowledge-ascription appears denotes that relationship. As we saw in section 1 above, constructions can alter the relations that verbs express. The examples discussed in that section were of intransitive verbs (sparkle and bark) to which additional arguments had been added. A more complex case of argument augmentation, and one closer to the case of learn, know and other knowledge-ascription verbs, is that in which an already transitive verb takes a direct-object argument distinct from the one it intrinsically assigns. The verbs win and drink will here be used to illustrate this case. Intuitively speaking, the verb win expresses a relationship between a contestant and a prize, and drink a relationship between a person and a liquid, but these are not the relationships denoted by the constructions in (17-18), respectively:

17. He won me a stuffed animal.

18. He drank himself into a stupor.

Sentence (17) illustrates the Ditransitive (or 'double object') construction, whose (active voice) form is a verb followed by two noun phrases (in (17), me and a stuffed animal, respectively) and whose direct object (i.e., me) denotes the recipient of a transferred item. Example (18) illustrates the Resultative construction, whose form is a verb followed by a NP and directional expression (in (18), himself and into a stupor, respectively), and whose direct object (i.e, himself) denotes something or someone who has undergone a 
change of state. In each of these two examples, there is a mismatch between the semantic roles that the verb calls for and those that the construction supplies: while winning requires only two participants (the victor and the prize), transfer requires three, and while drinking requires a direct object denoting a liquid, in (18) it gets a direct object denoting a human. Assuming the set of verb-construction integration relations described by Goldberg (1995), we can say that in (17) winning is understood to be a precondition for transfer while in (18) drinking is understood to be the means by which one moves (metaphorically) from sobriety to stupefaction. Notice in particular that the integration of the verb drink and the caused-motion construction in (18) requires the removal of the verb's ordinary second argument (the potable substance) and the replacement of that argument with one licensed by the construction: the affected-party argument. We understand that the drink's potable-substance argument is present conceptually (since one cannot drink without a liquid), but (18) denotes something that someone did to himself rather than to a beverage. In fact, the suppression of participant roles, and the consequent existential interpretation of those roles, is common in English and other languages (Fillmore 1986). For example, the verb drink allows null expression of the potablesubstance argument in a variety of frames:

19. She drank from a mug.

20. He drinks.

Significantly, argument omission is also licensed by verbs of knowledge like teach:

21. She teaches first graders.

While the speaker of (21) does not specify the content that the teacher causes her students to know, the relevant content is presumably inferable from context. Were the content argument to be present, it could be expressed by a noun phrase, as in (22):

22. She teaches first graders reading skills.

Like (18), (22) is an instance of the Ditransitive construction. This construction expresses an act of transfer, in which the direct object denotes a recipient and the second object (e.g., reading skills in (22) above) expresses the theme, or item transferred. (Most ditransitive verbs, including teach, are compatible with an alternate pattern in which the recipient is expressed by a preposition phrase, e.g., She gave a book to me.) While causing someone to know something is not literally an act of transfer, the fact that teach behaves syntactically as a transfer verb indicates that teaching can be construed according to the metaphorical mapping CAUSATION IS TRANSFER, also found in expressions like She gave me a headache and The judge handed him a victory (Lakoff 1993). Thus, the pattern of argument omission seen in (21) is the same as that in sentences like (23-24), in which the theme argument is likewise missing and recoverable from context:

23. She emailed me [the news].

24. Give me [that book].

Alternatively, the missing complement of (21) might be reconstructed as a finite clause introduced by the complementizer that, as in (25):

25. She teaches first graders that specific letter sequences correspond to words of English. 
Whether the content argument of teach is expressed by a noun phrase or a clause, it is subject to null expression, in which case it is reconstructed from context. The same analysis of teach holds when it is found in the pattern in (26):

26. She teaches first graders to read.

In (26), teach takes a subject (she) denoting an agent, a direct object (first graders) denoting an experiencer and an infinitival complement (to read) denoting an act. Following terminological tradition, we will refer to this construction as the Object Control construction. The Object Control construction is the transitive analog of the Infinitival Complement pattern exemplified in (13) above. Other examples of the Object Control construction are given in (27-28):

27. She convinced me to stay.

28. She forced me to agree.

Now, according to the Intellectualist model, the meaning of (26) is captured by the paraphrase in (29):

29. She teaches first graders that there is some $\mathrm{x}$ such that $\mathrm{x}$ is a way to read.

This analysis is implausible on its face. Instead, I would submit, the meaning of (26) is captured by the paraphrase in (30):

30. She teaches first graders propositional content that is a precondition to the act of reading.

According to the proposed analysis, (26) is an instance of argument augmentation by construction, as in (17-18). The added argument is the 'act' argument denoted by the infinitival verb. The construction that contributes this argument is Object Control. In the Object Control construction, the verb's direct object is interpreted as both the party affected by the act of teaching, forcing, persuading, etc. and the (potential) doer of the procedure denoted by the infinitival complement. When teach combines with the Object Control construction, two of the arguments of the verb undergo what Goldberg (1995: Ch. 2) refers to as fusion: they are identified with compatible arguments of the construction. The teacher argument of teach is fused with the agent (subject) argument of the Object Control construction and the student argument of teach is fused with the experiencer (object) argument of the Object Control construction. Where is the content argument of teach in (26)? It is missing: the content argument has not fused with an argument of the Object Control construction. In other words, the combination of the verb teach with the Object Control construction requires that the content argument be unexpressed: (31-32), for example, are ungrammatical:

31. * She teaches first graders reading skills to read.

32. *She teaches first graders that specific letter sequences correspond to words of English to read.

I submit that the ungrammaticality of (31-32) has the same source as that in (33):

33. *He drank liquor himself into a stupor.

Sentence (33) is a defective instance of the Resultative construction, a well-formed instance of which is shown in (18) above. Sentence (33) fails because verb-construction 
integration requires that the verb's second argument (liquor) be replaced by the construction's second argument (himself). The second argument assigned by the Resultative construction is an entity that undergoes a change of state; it is referred to as a theme argument. The label theme argument is used in frame-based semantics to denote a participant role that moves or is moved, either metaphorically, as in (18), where the state of stupefaction is construed as a location, or literally, as in (4), repeated here as (34):

34. She swept the dirt into a dustpan.

When a verb that selects for a specific type of direct object, like drink (a liquid) or sweep (a surface), appears without that direct object in the Resultative construction, the direct object in question is one that is omissible, as shown in (35-36):

35. The horses drank (water) thirstily.

36. She swept (the floor) thoroughly.

Crucially, however, while omission of the verb's theme argument is optional in (35-36), it is obligatory in the context of the Resultative construction, as shown by (33). The same observations can be made, mutatis mutandis, about the ill-formed examples in (31-31) above: verb-construction integration requires that the content argument, which is otherwise subject to omission, be replaced by the infinitival 'procedure' argument of the Object Control construction. It is important to notice that a general susceptibility to null expression is a necessary but not sufficient condition upon an argument's removal during verb-construction integration. As it happens, teach allows either the propositional-content argument or the 'student' argument or both to be unexpressed. The first pattern is exemplified by (21), repeated here as (37). The second and third patterns are exemplified by (38-39), respectively:

37. She teaches first graders.

38. She teaches reading skills.

39. She teaches.

But sentence (40), in which the 'student' argument has been removed in the course of verb-construction integration, is ungrammatical:

40. * She teaches reading skills to read.

Sentence (39) is ungrammatical because the Object Control construction requires an experiencer argument as its second argument, and the 'student' argument of teach is the only one of the two nonsubject arguments with the requisite properties of animacy and volition.

Thus far, we have discussed the combination of a transitive verb of knowledge ascription, teach, with a construction, the Object Control construction, that licenses an infinitival complement denoting a procedure. Similar observations apply to the combination of an intransitive verb of knowledge ascription with an infinitival complement. In contrast to French, German and other languages, where a stative verb of knowing can be combined with an infinitival complement denoting a procedure (as in the French savoir example (16) above), the only intransitive verb of knowledge ascription that enters into this pattern in English is the change-of-state verb, learn, which I will regard as meaning 'come to know some propositional content'. Thus, while (41) means something like 'I came to 
know something that enables me to swim', (42) does not mean 'I know something that enables me to make coffee'; rather, it means 'I know that I should make coffee under certain circumstances':

41. I learned to make coffee.

42. I know to make coffee.

While this divergence between know and learn is mysterious, the generally idiosyncratic behavior of verbs leads us to expect such cross-linguistic differences in verb complementation patterns, and the observations made here about the English verb learn can easily be applied to French savoir or German wissen. What is crucial for our purposes is that the grammatical pattern in (41) appears both grammatically and semantically analogous to that in (43):

43. I tried to make coffee.

The grammatical pattern exemplified in both (41) and (43) is referred to in the linguistic literature as Subject Control. Like Object Control, the Subject Control construction requires a single argument, the subject argument, to play a distinct semantic role for each of two verbs, the main verb and its infinitival complement. These roles are: the experiencer of the intentional state denoted by the finite verb (learn or try) and the agent of the procedure denoted by the infinitival verb (to make coffee). While in the Object Control construction this 'double duty' argument is the direct object of the main verb, in the Subject Control pattern it is the subject of the matrix verb. Like Object Control, Subject Control can replace the second argument of a verb with which it combines. In the case of (41), for example, the second argument, the propositional-content argument, is replaced by the infinitival 'procedure' argument of the construction. As in the case of teach, we find independent attestation of this argument-omission affordance for learn, in examples like (44-45):

44. I love to learn [things].

45. Will they ever learn [that crime doesn't pay]?

Thus, as in the case of teach, the version of learn that combines with the Subject Control construction is the intransitive one, in which the 'content' argument is not overtly expressed but is present at the conceptual level. As in the case of teach, the verbconstruction integration relation attested in such combinations is the precondition relation: learning some set of propositions (the content) is a precondition for doing things like making coffee.

The addition of an infinitival or clausal complement to the argument array of a mentalstate predicator (verbal or adjectival) is a general phenomenon, attested for predicators other than those expressing knowledge states, as in (46-48):

46. "I am slack jawed to read that members claim to have not understood that the techniques on which they were briefed were to actually be employed [...]," Mr. Goss wrote in The Wall Street Journal. (NY Times 5/14/09)

47. Griffin appears happy that he could be heading to Los Angeles.

48. Fergie was smart to dye her hair dark before getting married to Josh Duhamel. 
Both being slack-jawed and being happy are single-argument property predications. The clausal second argument with which these adjectives are paired in (46-47), respectively, is licensed by a construction rather than by the particular adjective. The construction exemplified in (46) is that which pairs a mental-state predicator with an infinitival clause denoting an activity that induces this mental state; it is also exemplified by (49):

49. I am embarrassed/shocked/surprised to read this news.

In (46), the state of being slack jawed (a facial posture) is used to represent the mental state of being shocked, according to the metonymic convention by which the symptom of an emotional state stands for that state. The integration relation illustrated in (46), as in (49), is the manner relation: the facial posture accompanies the state of being surprised. The construction exemplified in (47), described by Moffett (2005), denotes a relation between a thinker or speaker and propositional content believed or stated; the latter is expressed by a finite clause. Verbs and adjectives that select for this argument array on the basis of their intrinsic semantics are aware, believe and know. The adjective happy differs from the foregoing predicators in that it does not intrinsically select for a propositional argument: being happy is not necessarily the result of knowing some proposition. It is only by virtue of combining with the that-clause complementation pattern, as in (47), that happy obtains a propositional argument. The integration relation exemplified in (47) is again manner: the emotional state of happiness accompanies the intentional state of knowing (in this case, that one is heading for Los Angeles). The construction exemplified in (48), described by Oshima (2009) as the adj+to-inf construction, pairs an adjective that describes a mental or behavioral propensity of an individual (e.g., intelligence, boldness, bravery, stupidity) with an infinitival complement denoting an action ascribable to that propensity. In line with the present approach, Oshima describes this construction as follows:

The traditional argument/adjunct distinction tends to be obscured in 'non-canonical' constructions like the adj-to-inf-cxn. The to-infinitive is an indispensable constituent in the construction, and can be regarded as a complement in that respect; on the other hand, it may be considered an adjunct for the reason that the main predicate (adjective) does not inherently select for it. (Oshima 2009: 367)

In Construction Grammar terms, the infinitival complement is licensed by the adj-to-inf construction rather than by the adjective itself. In other words, adjectives like smart, stupid and wise are not intrinsically relational adjectives; in this respect they differ from intentional-state adjectives like eager, prepared and determined: felicitous use of sentences like Fred is eager/prepared/determined requires mutual knowledge of the act that Fred intends to perform, while no such requirement obtains for sentences like Fred is bold/smart/brave. Thus, adjectives like smart and stupid receive an infinitival complement only through the mechanism of word-construction integration. What is the integration relation exemplified by predications like (48)? As in the case of verbs of knowledge ascription, it is the precondition relation: having the relevant propensity is a necessary condition on performing the action, and so one can infer the propensity from the performance of the action. The latter statement captures Oshima's observation that predications licensed by the adj-to-inf construction are implicit epistemic conditionals; for example, as he observes (p. 370), the sentence John was wise to leave early can be 
paraphrased as 'John must have been being wise, \{because/considering that he left early'.

The foregoing observations show that syntactic context, or more specifically constructional context, may alter the array of semantic arguments that a verb or adjective selects. This means that the syntactic context may only indirectly reflect the semanticrole-licensing properties of the predicator. Acknowledging this enables us to strike a compromise between the Rylean and Intellectualist views: verbs like learn and teach do indeed take propositions as their second arguments, but that propositional argument is replaced by one denoting a procedure in the infinitival constructions that have convinced proponents of the Rylean view that verbs of knowledge ascription describe a relationship between a person and a procedure. Instead, as in the Intellectualist view, verbs of knowledge ascription denote a relationship between a person and propositional content. Such verbs are compatible with the Object Control and Subject Control constructions insofar as propositional knowledge is understood as a prerequisite for performance of the procedure. We here adopt the Rylean rather than Intellectualist view of infinitival complements: such complements denote procedures rather than propositions. The present account is thus Rylean with regard to constructional argument licensing and Intellectualist with regard to verbal argument licensing. At least in the case of verb phrases like French savoir nager and English learn to swim, the distinction between 'knowing how' and 'knowing that' comes down to a distinction between verb meaning and construction meaning.

\section{WH-complements}

A WH-clause consists of a predication in which a clause-initial question word (who, what, where, how, etc.) serves the function of an argument (e.g., agent or patient) or adjunct (e.g., means, manner, purpose). A WH-clause becomes a WH-complement (also known as an indirect question) when it serves as the argument of a verb, e.g., a speechact verb or verb of knowledge ascription. Sentence (50) is an example of the latter type of embedding context; I will argue that its meaning is captured by (51):

50. John knows how to make good coffee.

51. There is $\mathrm{x}$ means by which one makes good coffee, and John knows the value of $\mathrm{x}$.

Similarly, I propose that (52) means something like (53):

52. John wonders how to make good coffee.

53. There is $x$ means by which one makes good coffee, and John wants to learn the value of $\mathrm{x}$.

In other words, WH-complements of verbs of knowledge ascription are just like WHclauses in general: first, they presuppose an open proposition (i.e., one containing an unbound variable in place of an argument or adjunct) and second, the embedding construction expresses what the speaker's stance ${ }^{2}$ toward that variable is: the speaker may

\footnotetext{
${ }^{2}$ By speaker stance here I mean either the stance of the person denoted by the subject of a verb of cognition or speaking, as in (50) and (52), or the stance of the person uttering the sentence, as in (54-55).
} 
have knowledge of its identity, as in (50), express lack of knowledge of its identity, as in (52), or provide its identity, as in (54) below: ${ }^{3}$

54. What I lost was my wallet.

a Presupposed: I lost $\mathrm{x}$

b Asserted: $x=$ my wallet

This analysis, while propositional, is distinct from the Intellectualist one, in that we view the propositional content conveyed by the WH-complement of a knowledge-ascription verb as presupposed rather than asserted. What is asserted is the speaker's stance toward the value of the variable. The assertion of speaker stance is what makes an utterance containing such a clause informative. In other words, a WH-clause alone conveys nothing more than an open proposition (as, for example, what I lost in (54) conveys 'I lost x'); it takes an embedding context to make such a clause into an assertion. Such embedding contexts need not be complementation contexts; they may instead be conversational or speech-act contexts. According to Lambrecht and Michaelis (1998), main-clause questions like (55) assert a speaker stance toward the variable, captured by (56):

55. What did you lose?

56. With regard to your having lost $\mathrm{x}, \mathrm{I}$ am inquiring about the value of $\mathrm{x}$

In exploiting properties shared by WH-complements across a variety of syntactic contexts, the present account resembles that of Stanley and Williamson (2001) and Stanley (2011), who take the formal similarity of know-how ascriptions to ascriptions of knowing-why, knowing-where, etc. as evidence that

knowing how to $F$ is in a family of mental states that include knowing where to $F$, knowing why to $F$, knowing when to $F$, etc., states that involve the normal knowing relation, together with an embedded question. (Stanley 2011: 226)

The current account, however, provides a semantico-pragmatic representation of $\mathrm{WH}-$ complements that makes sense regardless of the embedding verb; it is unclear whether

${ }^{3}$ The analysis given here of (54) is potentially controversial, since (54) is generally taken to exemplify a free relative-clause (i.e., the thing that I lost) rather than an indirect question. While the formal similarity between the two constructions creates ambiguities, as in (a), which has both a free-relative and an indirect-question paraphrase, as indicated in (b-c), respectively, certain syntactic tests distinguish the two patterns.

(a) I asked what she asked.

(b) I asked the question that she had asked. (free relative)

(c) I inquired about what she had asked. (indirect question)

One such test is described by Zwicky and Sadock (1975): insertion of the modifier the hell, as in (d), allows for only the indirect-question interpretation:

(d) I asked what the hell she asked.

While such facts suggest that free relative clauses and WH-clauses are indeed distinct construction, I maintain that the former can revealingly be treated as denoting an open proposition in equative predications like (54). 
the same could be said of the Intellectualist account. Stanley (2011) asserts, for example, that (57) has the paraphrase given in (58):

57. John knows how to find coffee in New York City. (Stanley 2011, (1d))

58. For some way w, John knows that he can find coffee in New York City in way w. (Stanley 2011, (2d))

This seems reasonable, and yet the proposed paraphrase relation appears to be restricted to sentences containing factive verbs like know. It does not appear to hold, for example, when we replace the verb know with the verb ask: (60) is not a valid paraphrase of (59):

59. John asked how to find coffee in New York City.

60. For some way w, John asked whether w was a way to find coffee in New York City.

When John asks how to find coffee in New York City, he is not inquiring about the efficacy of a coffee-locating method that he already has in mind (say, using an iPhone application). Instead, he is seeking to discover a method. Because the paraphrase in (60) contains a wide-scope existential quantifier over methods, it does not capture what is going on in a context of inquiry, where the person making the inquiry does not yet know of a particular method, but only takes for granted that there is one. If, however, we translate the WH-complement how to find coffee in New York City as a proposition containing an unbound 'means' variable (i.e., 'one finds coffee in $\mathrm{x}$ way in New York City'), and analyze the matrix verb ask as an indicator of the speaker's stance toward that variable, it is easy to describe the meaning of (59): it asserts that John inquired about the value of a 'means' variable, just as (50) asserts that John knows the value of a 'means' variable. In other words, the current account may come closer to the compositional ideal than the Intellectualist one, in that it gives the same analysis of WH-clauses regardless of embedding context. In the present analysis, the true second argument of the verb know in (50), the verb wonder in (52) or the verb ask in (59) is not an open proposition but the variable contained within that open proposition.

Is an unbound variable the kind of thing that can be an argument? A recent study by Birner, Kaplan and Ward (2007) suggests that the answer is yes. This study examines the family of argument-structure constructions consisting of that-clefts (e.g., That's John who wrote the book), equative clauses containing the epistemic verb would and a demonstrative subject (e.g., That would be John) and simple equatives with demonstrative subjects (e.g., That's John). The latter two constructions, they argue, should not be analyzed as truncated clefts (pace Hedberg 2003). That is, they reject the view that (61) is an elliptical version of (62):

61. That's John.

62. That's John who's knocking on the door.

Instead, they argue, all three constructions inherit formal, semantic and informationstructure properties from an argument-focus construction used for equative assertions. This construction contains a copular verb and a demonstrative subject, and it presupposes an open proposition whose variable is referred to by the demonstrative subject. The focal expression following the verb be provides the value of this variable, as in other argumentfocus predications (e.g., I saw JOHN). Thus, for example, in (61), the demonstrative subject refers to the variable in a presupposed open proposition, ' $\mathrm{x}$ is at the door'. 
But if the variable is the true second argument of a verb that takes a WH-complement, where is the propositional content of the WH-complement in our representation? It is in the presupposition, as indicated by the existential clauses in the paraphrases of (50) and (52). For example, (51), the paraphrase provided for (50), John knows how to make good coffee, contains the existential clause 'there is x means by which one makes good coffee'. Patterns of ellipsis in WH-complements support the view that the open proposition is presupposed rather than asserted: in a pattern called sluicing by Ross (1969), only the question word is present; the predication in which the question word plays an argument role is deleted on the supposition that it is recoverable:

63. Sue can make good coffee but I don't know how [...].

64. I left my keys somewhere, but I don't know where [...].

The fact that the open proposition is omissible under conditions of contextual recoverability follows from its status as a topic, i.e., the entity or proposition about which the speaker is providing new information (Lambrecht 1994: Chapter 4, Lambrecht and Michaelis 1998). Topical arguments are predictable arguments; speakers omit them because hearers can reconstruct them from context. In the case of knowledge-ascription predications like (57), John knows how to find coffee in New York City, the topical proposition is the open proposition 'One finds coffee in New York City using x method'. The topic status of the open proposition is further substantiated by synonymy relations like that in (65-66):

65. I know how to make good coffee.

66. I know the way to make good coffee. ${ }^{4}$

In (66), a noun phrase is used in place of a WH-complement. It is significant that this noun phrase contains the definite article, which elsewhere evokes an existence presupposition: both (65) and (66) take for granted that there is some way to make good coffee. Thus, while Stanley (2011) is correct in asserting that, e.g., the sentence John knows how to find coffee in New York City (sentence (57) above) "is naturally read as expressing the proposition 'For some way w, John knows that he can find coffee in New York City in way w'” (p. 4), his analysis fails to distinguish between asserted and

4 The complementation pattern exemplified by (66) may be unique to English. For example, French native speakers find its direct translation ungrammatical:

(a) *Je sais la manière de faire du bon café.

Such cross-linguistic differences in verb complementation patterns are not unexpected, even in closely related languages. For example, while the complementation pattern exemplified in (64) is also found in French, as in (b), it is ungrammatical in German (c), which requires a finite clause instead, as in (d):

(b) Il ne sait pas comment répondre. ('He doesn't know how to respond.')

(c) *Er weiss nicht, wie zu antworten

(d) Er weiss nicht, wie er antworten soll. (lit. 'He doesn't know how one should respond.') 
presupposed parts of that proposition. This sentence does not assert that John knows that there are ways to find coffee in New York City. Instead, it presupposes that there are ways to find coffee in New York City. It asserts that John knows one or more of those ways, i.e., one or more values of the 'means' variable.

\section{Conclusion}

Neither the Intellectualist nor the Rylean model provides an adequate semantic analysis of the two major complementation patterns attested for verbs of knowledge ascription, namely, the infinitival and WH-complement patterns. The Intellectualist model perhaps comes closer, in that it correctly assesses such verbs as expressing a relationship between a person and a proposition. The problem with the Intellectualist model, as I see it, is that neither the infinitival-complement construction nor the WH-complement construction actually denotes this relationship. I have argued that the infinitival-complement pattern denotes a relation between a person and a procedure, where propositional knowledge represents a precondition for performing the procedure, and that the WH-complement pattern denotes a relation between a person and a 'means' variable in a presupposed open proposition - namely, the ability to identify that variable. The moral of this story is that the grammar of knowledge attribution is not monolithic, but is instead a constellation of constructions, each with its own array of semantic roles and use conditions.

But why should the grammar of English (or any other language) offer speakers two different ways of saying essentially the same thing? Put differently, what pragmatic considerations induce a speaker to use the infinitival-complement construction rather than the WH-complement construction when formulating a knowledge-ascription predication? We can gain some insight into this question by contrasting reports of mundane abilities, like those in (67-68), with reports of refined abilities, like those in (69-70):

67. Sue learned to swim.

68. Sue learned how to swim.

69. Sue learned to change lanes quickly.

70. Sue learned how to change lanes quickly.

While (67), (68) and (70) all assert that Sue attained knowledge required to perform a procedure, (69) seems instead to assert that Sue attained knowledge of when to use an already mastered ability. In this respect, (69) appears similar to (71):

\section{Sue knows to swim.}

If (71) means anything, it means 'Sue knows that one ought to swim (under some conditions)'. By the same token, (69) means something like 'Sue learned that one ought to change lanes under some conditions'. It makes sense that (71) should have a deontic reading, since, as observed above in connection with example (42), the English verb know otherwise fails to license the infinitival-complement pattern. However, the English verb learn is clearly compatible with the infinitival-complement pattern. What then accounts for the deontic flavor of (69)? Comparison with French gives some clue. Native speakers report the pattern of grammaticality in (72-73):

72. Elle sait (??comment) nager.

lit. 'She knows (??how) to swim.' 
73. Elle sait *(comment) changer de voie rapidement.

lit. 'She knows *(how) to change lanes rapidly.'

As (72) shows, while the bare-infinitive form is preferable to the WH-infinitive form for nager ('swim'), the reverse pattern holds for the more complex verb phrase changer de voie rapidement, as shown in (73). If we assume that the infinitival complement denotes a mundane skill while the WH-complement denotes a rarer skill, this pattern makes sense: the opposition seen in (69-70), and (72-73), may be a case of linguistic iconicity (Haiman 1980, 1983). According to Haiman's quantity principle, linguistic complexity reflects conceptual complexity, and it therefore stands to reason that the less elaborate complementation pattern (the bare infinitive) should denote a more conventional skill than the more elaborate complementation pattern (the WH-complement).

\section{References}

Birner, Betty, Jeffrey Kaplan and Gregory Ward 2007. Functional Compositionality and the Interaction of Discourse Constraints. Language 83: 317-343.

Fillmore, Charles J. 1986. Pragmatically Controlled Zero Anaphora. In V. Nikiforidou, M. Van Clay, M. Niepokuj and D. Feder, (eds.), Proceedings of the Twelfth Annual Meeting of the Berkeley Liguistics Society. Berkeley: Berkeley Linguistics Society.: 95-107.

Goldberg, Adele. 1995. Constructions: A Construction Grammar Approach to Argument Structure. Chicago: University of Chicago Press.

Haiman, John. 1980. The Iconicity of Grammar: Isomorphism and Motivation. Language 56: $515-540$.

Haiman, John. 1983. Iconic and Economic Motivation. Language 59: 781-819.

Hedberg, Nancy 2000. The Referential Status of Clefts. Language 76: 891-920.

Jackendoff, Ray. 1997. The Architecture of the Language Faculty. Cambridge, MA: MIT Press.

Kay, Paul and Charles J. Fillmore. 1999. Grammatical Constructions and Linguistic Generalizations: The 'what's X doing Y' Construction. Language 75: 1-33.

Kay, Paul. 2002. English Subjectless Tag Sentences. Language 78: 453-81

Lakoff, George. 1993. The Contemporary Theory of Metaphor. In A. Ortony, (ed.), Metaphor and Thought. Cambridge: Cambridge University Press. 202-251.

Lambrecht, Knud. 1994. Information Structure and Sentence Form. Cambridge: Cambridge University Press.

Lambrecht, Knud and Laura A. Michaelis. 1998. Sentence Accent in Information. Questions: Default and Projection. Linguistics and Philosophy 21: 477-544.

Moffett, Marc. 2005. Constructing Attitudes. Protosociology (Compositionality, Concepts and Representations I: New Problems in Cognitive Science) 21: 105-128

Oshima, David. 2009. Between being Wise and Acting Wise: A Hidden Conditional in Some Constructions with Propensity Adjectives. Journal of Linguistics 45: 363393.

Ross, John. R. 1969. Guess who? In R. Binnick, A. Davison, G. Green and J. Morgan, (eds.), Papers from the Fifth Regional Meeting of the Chicago Linguistic Society. Chicago: Chicago Linguistics Society. 252-286.

Michaelis, Laura A. 2004. Type Shifting in Construction Grammar: An Integrated Approach to Aspectual Coercion. Cognitive Linguistics 15: 1-67. 
Sag, Ivan A. 2010. English Filler-Gap Constructions. Language 86: 486-545.

Stanley, Jason. 2011. Knowing How. Nous 45: 207-238.

Stanley, Jason and Timothy Williamson. 2001. Knowing How. The Journal of Philosophy 98: 411-444.

Zwicky, Arnold \& Jerrold Sadock. 1975. Ambiguity Tests and how to Fail them. In P. Kimball, (ed.), Syntax and Semantics 4. NY: Academic Press, Inc. 1-36. 